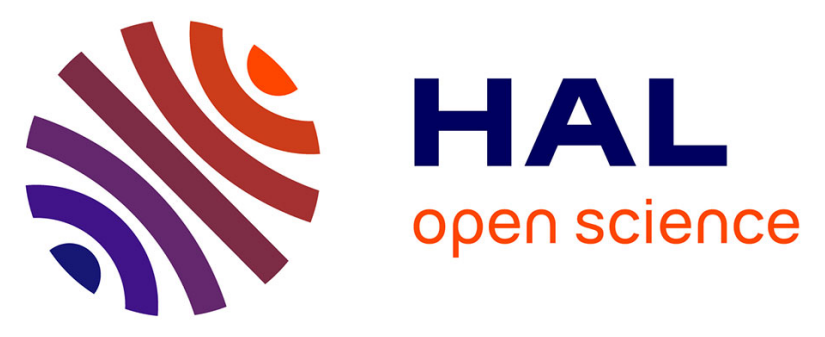

\title{
Polarization Control of a Metal-Only Transmitarray Unit-Cell
}

\author{
Kien Pham, Ronan Sauleau, Erwan Fourn, Fatimata Diaby, Antonio
}

Clemente, Laurent Dussopt

\section{- To cite this version:}

Kien Pham, Ronan Sauleau, Erwan Fourn, Fatimata Diaby, Antonio Clemente, et al.. Polarization Control of a Metal-Only Transmitarray Unit-Cell. 2018 IEEE International Symposium on Antennas and Propagation and USNC-URSI Radio Science Meeting, Jul 2018, Boston, United States. 10.1109/apusncursinrsm.2018.8609344 . hal-02053235

\section{HAL Id: hal-02053235 https://hal.science/hal-02053235}

Submitted on 1 Mar 2019

HAL is a multi-disciplinary open access archive for the deposit and dissemination of scientific research documents, whether they are published or not. The documents may come from teaching and research institutions in France or abroad, or from public or private research centers.
L'archive ouverte pluridisciplinaire HAL, est destinée au dépôt et à la diffusion de documents scientifiques de niveau recherche, publiés ou non, émanant des établissements d'enseignement et de recherche français ou étrangers, des laboratoires publics ou privés. 


\section{Polarization Control of a Metal-Only Transmitarray Unit-Cell}

\author{
Kien Pham ${ }^{1,2}$, Ronan Sauleau ${ }^{1,2}$, Erwan Fourn ${ }^{1,3}$ \\ ${ }^{1}$ IETR, UMR CNRS 6164, France \\ ${ }^{2}$ Université de Rennes 1, 35042 Rennes Cedex, France \\ ${ }^{3}$ INSA de Rennes, CS70839, 35708 Rennes Cedex \\ trung-kien.pham.1@univ-rennes1.fr, ronan.sauleau@univ- \\ rennes1.fr, erwan.fourn@insa-rennes.fr
}

\author{
Fatimata Diaby, Antonio Clemente, Laurent Dussopt \\ CEA, LETI, MINATEC Campus, 38054 Grenoble \\ Université Grenoble-Alpes, 38000 Grenoble \\ Grenoble, France \\ fatimata.diaby@cea.fr, antonio.clemente@cea.fr, \\ laurent.dussopt@cea.fr
}

\begin{abstract}
This paper presents a metal-only transmitarray unit-cell exhibiting polarization twisting which allows reducing side lobe level of transmitarray radiation. This dominant capability is proposed and illustrated by two versions of a metalonly unit-cell consisting of four or three identical layers separated by quarter-wavelength spacers at $18.75 \mathrm{GHz}(4 \mathrm{~mm})$. The unit-cell is based on C-shaped slot, and the phase variation is achieved by varying the inner radius of the slot. The linear polarization is twisted by gradually rotating consecutively each layer with the same rotation angle.
\end{abstract}

Keywords - metal-only transmitarray, Ka-band, Satcom

\section{INTRODUCTION}

Transmitarray antennas (TAs) are alternatives to traditional antenna types like reflectors or phased-arrays, for future highgain applications thanks to its spatially-fed configuration and flat radiating aperture. Many TA prototypes have been demonstrated in the past by using printed circuit board (PCB) technology; however the associated fabrication cost may remain expensive for commercial extremely low-cost applications. This motivates the current strong interest in cheap solutions called metal-only transmitarray antennas (MOTAs). Successful experiments have been demonstrated in X-band [1] and Ku-band [2] with good radiation characteristics.

Polarization manipulation is presented in several transmitarray prototypes realized by $\mathrm{PCB}$ fabrication. The main key point of these configurations is based on via-hole structures in which the receiving and transmitting layers are separated by a common ground plane, and they interact each other by a via, as described in [3],[4]. Therefore the polarization at each side of the unit-cell depends on their patch geometries and orientation, which can lead to different polarization directions. In other prototypes, polarization manipulation is implemented by stacking patches with variable length and width to convert linear to circular polarization by differentiating $90^{\circ}$-transmitted phase between orthogonal linear polarized (LP) waves (e.g. [5]). When using MOTAs, there is no substrate, and microstrip patches cannot stand alone without support; hence, implementation of this capability is restricted. We introduce here a new technique to twist the LP incident wave to arbitrary LP transmitted wave with capability of beam forming in specific direction.

This works is supported by the French National Research Agency (ANR) in the project named TRANSMIL (TRANSmitarray antenna at MILlimeterwave) under Grant ANR-14-CE28-0023.
The unit-cell is based on a wideband C-shaped slot frequency selective surface exhibiting spectral bandpass filter. The rotation technique is applied for each layer to change the polarization at radiating side. In this work we illustrate polarization control of low-cost MOTAs in the Satcom downlink K-band (17.7-21.2 GHz). The technique to control polarization is described in Section II. The numerical results are presented in Section III with polarization conversion from $y$-direction to $x$ - or $45^{\circ}$-inclined direction.

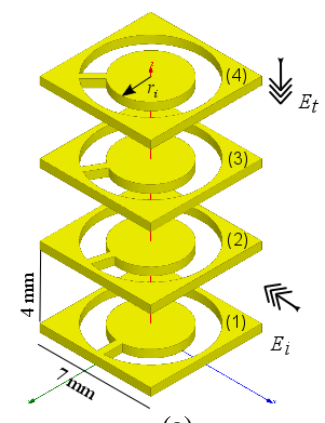

(a)

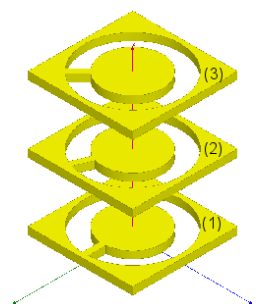

(b)
Fig. 1. MOTA unit-cell converting $y$-polarized incident wave to $45^{\circ}$-inclined polarized outgoing wave: (a) Four-layer design, and (b) three-layer design.

\section{POlarization CONTROL TECHNIQUe}

Twisting polarization orthogonally between receiving and transmitting side of transmitarray is an effective way to reduce the side lobe level [6] when part of it is due to spill-over radiation from feeding horn [7]. The three-dimensional geometry of the proposed unit-cell is depicted in Fig. 1 for a particular case illustrating polarization conversion from $y$ direction to $45^{\circ}$-inclined direction. The unit-cell proposed in this paper is an evolution of the linearly-polarized C-slot unitcell described in [8]. The unit-cell edge is $7 \mathrm{~mm}$, and the metal layer thickness equals $500 \mu \mathrm{m}$. A multi-layer configuration is selected to provide a phase-shift with a separation of $4 \mathrm{~mm}$ between two consecutive layers (see Fig. 1a for the four-layer design and Fig. $1 \mathrm{~b}$ for the three-layer one). The transmission phase is shifted by varying the inner radius $r_{i}$ of the C-shaped slot, as shown in Fig. 1 with fixed outer radius of $3.3 \mathrm{~mm}$.

For the 4-layer case (Fig. 1a), polarization control is obtained by rotating uniformly the C-shaped slots of three layers (layers \#2, \#3 and \#4) consecutively by an equal amount 
of angle so that the field radiated by the last layer (layer \#4 in Fig. 1) is polarized in the desired direction. This is applicable to any unit-cell in stacked configuration with at least three layers.

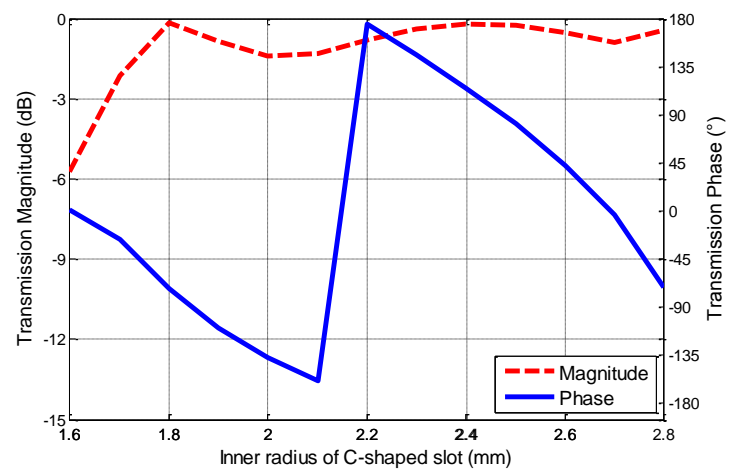

Fig. 2. Transmission coefficients in magnitude and phase as a function of the inner diameter $r_{i}$ for $x$-polarization of the four-layer MOUC.

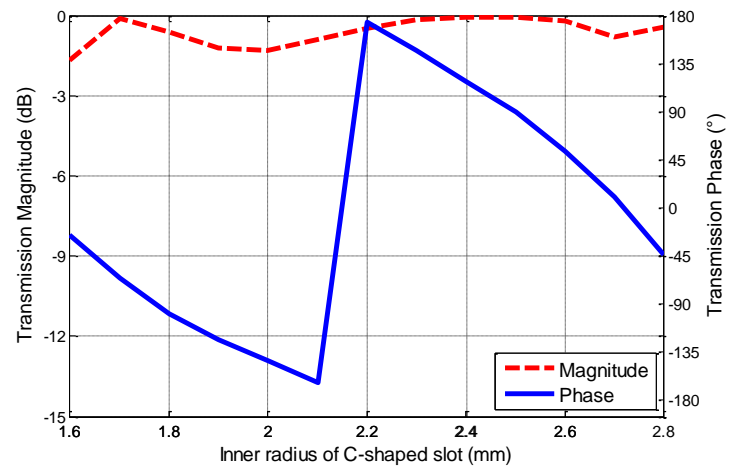

Fig. 3. Transmission coefficients in magnitude and phase versus the inner diameter $r_{i}$ for $45^{\circ}$-inclined polarization for four-layer MOUC.

\section{PARAMETRIC STUDY}

The metal-only unit-cells (MOUC) have been characterized numerically by full-wave simulations using Ansys HFSS v.15 with periodic boundary conditions. The MOUCs are excited by two Floquet ports at the bottom (Port 1) and top (Port 2) to compute the two-port scattering matrix. Demonstration of polarization twisting is provided for two cases: (i) $x$-polarized and (ii) diagonally-polarized outgoing wave. In all cases the incident wave is polarized along $y$-axis. In the first case, for the four-layer MOUC (Fig. 1a), the rotation angle is $15^{\circ}$ between each layer, while in the second case, this angle equals is $30^{\circ}$. For the three-layer design (Fig. $1 \mathrm{~b}$ ), rotation angles equal $22.5^{\circ}$ and $45^{\circ}$ for cases (i) and (ii) respectively. The transmission coefficients for case (i) is denoted by $S_{21}^{x y}$ while for case (ii) it is derived as follows

$$
S_{21}^{45^{\circ}-y}=\frac{1}{\sqrt{2}}\left(S_{21}^{x y}-S_{21}^{y y}\right)
$$

The transmission coefficients at $19 \mathrm{GHz}$ are depicted in Fig. 2 and Fig. 3 for cases (i) and (ii), respectively. In both cases, the unit-cells exhibit a phase-shift of $360^{\circ}$ with insertion loss below $1.5 \mathrm{~dB}$ when the inner radius varies between 1.8 $\mathrm{mm}$ and $2.8 \mathrm{~mm}$ or from $1.6 \mathrm{~mm}$ to $2.8 \mathrm{~mm}$ in case (i) or case (ii), respectively. As nearly-linear transmission phase curves are observed, the proposed unit-cells are rather robust with respect to fabrication uncertainties (around $50 \mu \mathrm{m}$ by laser machine). For both polarization scenarios, the characteristics of the MOTA unit-cell are very promising and suitable for realization of MOTAs.

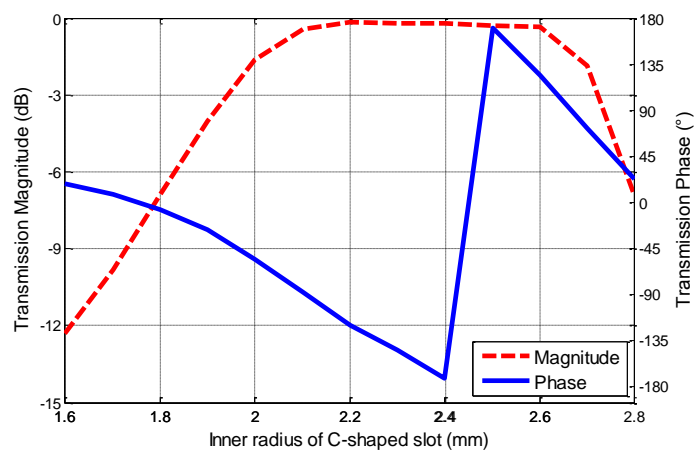

Fig. 4. Transmission coefficients in magnitude and phase as a function of the inner diameter $r_{i}$ for $x$-polarization of the three-layer MOUC.

This technique is also eligible for three-layer unit-cell in both cases; nevertheless, phase range is reduced to around $270^{\circ}$ with transmission magnitude better than $-3 \mathrm{~dB}$ at $19 \mathrm{GHz}$ (see Fig. 4, transmission coefficients in the case (i) for $x$-polarized output wave). The similar behavior is also observed in the case (ii) for the three-layer MOUC.

\section{CONCLUSIONS AND PERSPECTIVES}

Metal-only unit-cells based on C-shaped slot have demonstrated a capability of linear polarization manipulation. This characteristic is very convenient to obtain desired polarization direction for a low-cost transmitarray solution. This unit-cell is possibly scalable to adapt many frequency bands to serve plenty of applications (5G Satcom links, frontand backhaul links, etc...).

\section{REFERENCES}

[1] A. H. Abdelrahman, A. Z. Elsherbeni, and F. Yang, "Transmitarray antenna design using cross slot elements with no dielectric substrate," IEEE Antennas Wireless Propag. Lett., vol. 13, pp. 177-180, 2014.

[2] R. Y. Wu, Y. B. Li, W. Wu, C. B. Shi, and T. J. Cui, "High-gain dualband transmitarray," IEEE Trans. Antennas Propag., vol. 65, no. 17, pp. 3481-3488, Jul. 2017.

[3] W. Pan, C. Huang, X. Ma, B. Jiang, and X. Luo, "A dual linearly polarized transmitarray element with 1-bit phase resolution in x-band," IEEE Antennas Wireless Propag. Lett., vol. 14, pp. 167-170, 2015.

[4] L. Di-Palma, A. Clemente, L. Dussopt, R. Sauleau, P. Potier, and P. Pouliguen, "Circularly-polarized reconfigurable transmitarray in Kaband with beam scanning and polarization switching capabilities," IEEE Trans. Antennas Propag., vol. 65, no. 2, pp. 529-540, Feb. 2017.s

[5] C. Tian, Y. C. Jiao, and G. Zhao, "Circularly polarized transmitarray antenna using low-profile dual-linearly polarized elements," IEEE Antennas Wireless Propag. Lett., vol. 16, pp. 465-468, 2017.

[6] K. T. Pham, R. Sauleau, E. Fourn, F. Diaby, A. Clemente, and L. Dussopt, "Dual-band transmitarrays with dual-linear polarization at Kaband," IEEE Trans. Antennas Propag., vol. 65, no. 12, pp. 7009-7018, Dec. 2017.

[7] K. Pham, N. T. Nguyen, L. Le Coq, R. Sauleau, A. Clemente, and L. Dussopt, "Design of wideband dual linearly polarized transmitarray antennas," IEEE Trans. Antennas Propag., vol. 64, no. 5, pp. 20222026, May 2016.

[8] K. T. Pham, R. Sauleau, E. Fourn, F. Diaby, A. Clemente, and L. Dussopt, "Metal-only transmitarray based on C-shaped slot," submitted to 2018 IEEE Intern. Symp. Antennas Propag. (APSURSI), Boston, MA, USA. 
